\title{
Use Of A Real World Business Panel To Assist In MBA Program Outcomes Assessment And Curriculum Refinement
}

Joseph G. Glynn, (E-mail: glynn@ canisius.edu), Canisius College Richard A. Shick, (E-mail: shick@canisius.edu), Canisius College

\begin{abstract}
The world of business operates in an extremely dynamic environment. Domestic issues (competition, cultural diversity, regulation/deregulation) global issues (competition, economic, cultural/social, and political), and rapidly changing technologies all require business school curricula that are designed to be flexible and proactive as well as reactive. An ever increasingly important responsibility of schools of business is the assessment of outcomes of their programs. Outcomes may be measured on several dimensions. One such measurement is the assessment of the skills/abilities of its graduates. This work will describe the efforts of a business school to engage the local business community in that undertaking.
\end{abstract}

\section{Introduction}

$B$ enchmarking, outcomes measurement and continuous improvement are issues that very much concern business schools at this time. Increasingly schools are being called upon to demonstrate that the curricula and courses they offer are serving the educational needs of their students and the business community. Schools are highly motivated to demonstrate that graduates have attained the knowledge, skills and competencies that are the goals of the educational process.

While the desire to meet the educational needs of various stakeholders is not new, it is becoming increasingly critical as various accrediting bodies build such expectations into their standards. For example, AACSB International, the specialized accrediting agency for collegiate schools of business, requires their accredited members to develop and maintain processes designed to produce stated outcomes, ensure continuous improvement and provide evidence that the desired outcomes have been achieved. On a regional basis the Middle States Commission on Higher Education's newly published Characteristics of Excellence in Higher Education, 2002 has a standard on institutional assessment (Standard 7) and a standard on assessment of student learning (Standard 14).

In this environment, it is not surprising that many different ways of measuring competencies and outcomes have been developed. National organizations such as Educational Benchmarking, Inc. and Educational Testing Service have developed tests that can be used by a school to benchmark its graduates against other selected schools. Additionally, countless individual alumni surveys have been developed and administered. The purpose of this paper is to report on another outcomes measurement technique that was developed and used at an accredited business school.

\section{Background}

The study was undertaken in a business school at a small private college in the northeastern part of the United States. The business school offers programs at both the undergraduate and graduate levels and enrolls approximately 900 undergraduate students and 400 graduate students. It has been accredited by the AACSB

Readers with comments or questions are encouraged to contact the authors via email. 
International since 1982. The largest graduate program is a part-time MBA with approximately 300 students taking classes in the evening.

The current graduate curriculum was implemented in 1995 after an extensive two-year review/design/development process that included wide consultation with various stakeholder groups. It has the following educational goals:

1. Development of graduates who are known for:

- technical and professional skills that allow them to make immediate contributions to their organizations,

- $\quad$ application of high ethical standards in decision-making,

- ability to manage effectively in a changing business environment,

- $\quad$ effective communication and information technology skills,

- $\quad$ ability to confront issues and solve problems in an organized and effective way by integrating a number of different disciplines,

- $\quad$ engagement in lifelong learning and professional development,

- $\quad$ interpersonal and team-building skills, and

- $\quad$ ability to work in the international community.

2. Offer a broad-based management education based on the decision-making process.

3. Encourage students to take a multidisciplinary approach to problem solving.

The business school surveys its undergraduate students, MBA students, and alumni on a regular basis to determine how well the goals are being achieved. With respect to the MBA Program, three distinct surveys are administered on a regular basis.

New MBA Student Survey - Students entering the program are surveyed concerning, among other items, their expectations, reasons for choosing the program, and ratings of the importance to them of items on lists of skills and business-related issues.

Graduating MBA Student Survey - During their last semester, MBA students are surveyed concerning how successful the program was with respect to the same lists of skills and business-related issues. The students are also asked to rate a variety of academic and administrative aspects of their program, and are provided the opportunity to express satisfaction/dissatisfaction in open-end format.

MBA Alumni Survey - Each year, the MBA class that graduated seven years earlier is surveyed. Respondents are provided the identical list of skills used on the New MBA Student and Graduating MBA Student Surveys described above. The alumni are asked to identify three skills in each of the following areas: (a) most improved, (b) least successfully developed, and (c) most important to your professional objectives and development.

In addition, the school wanted to obtain more regular and structured feedback from the business community that employs our students. We believed that the involvement of practitioners from the local business community would result in ideas that have a significant effect upon the degree to which we will achieve successful integration of course material and real world experiences in our MBA curriculum. Several approaches were attempted with little initial success. Meetings of the school's Business Advisory Council were held to discuss the perceptions of how well MBA graduates met the goals of our educational programs. The feedback from these sessions was very general in nature and many of the respondents were at such a high level in their organizations that they had only limited experience with the graduates. Further, in a group setting like the Business Advisory Council, discussions can be expected to be supportive in tone and gravitate towards positive attributes and outcomes of our programs and graduates. In a second attempt, a survey was sent to the businesses represented on the advisory council with a request that the instrument be routed to the individual in the best position to complete it. The initial response rate 
was very poor. As a follow-up a number of personal interviews with employers were conducted, but this approach was very time consuming and not as fruitful as anticipated. Thus after several less than successful attempts to obtain feedback from the business community, the approach described herein was undertaken.

\section{The Classroom Experience}

The MBA curriculum contains three integrating experiences. In the first two courses students work on textbook cases, but in the last course they work on a real business problem. The students are responsible for identifying an appropriate problem, getting an organization to cooperate in the process, developing a solution and presenting that solution in both a written report and a formal presentation to representatives of the organization. Over the years we have been offering this course, the organizations have been a mix of businesses and not-for-profit entities.

The representatives from the organizations supplying the problems attended classroom presentations of the case studies, and were surveyed following the receipt of the written reports. Results from the thirty-one surveys received provide an excellent opportunity to evaluate feedback on how well the students demonstrated competence with respect to the curriculum goals.

\section{Goals and Expected Benefits}

The terms "business practitioners, respondents, and panelists" will be used interchangeably throughout the rest of this work. We felt that the solicitation of information from business practitioners would directly and indirectly benefit faculty and students in several ways:

- $\quad$ The respondents would be polled with respect to which skills and abilities (i.e., writing, problem-solving, presentation, etc.) are most important in the business world. This information would be very important to faculty in the design of courses, evaluative exercises and instruments, and would underscore the necessity of integration of material both within and across courses.

- Using business practitioners to identify the major business-related issues: business ethics, international, globalization, leadership, functional areas, etc. This information would provide guidance to faculty in the development of individual courses, areas of concentrations, as well as continued overall curriculum refinement.

- $\quad$ The outcomes assessment would be provided by an important stakeholder group exogenous to the college. With respect to the skills and abilities described above, the panelists would be asked to identify those that were evident in a positive sense during student presentations and discussions. In like manner, panelists would identify less than successfully displayed skills and abilities. This feedback is of immeasurable value to faculty in the development and alteration of pedagogy and to students who would be motivated to devote more attention to the development of skills and abilities deemed to be important by members of the local business community.

\section{The Survey Instrument}

The survey was designed to be very brief and easy to fill out, while allowing for open-end comments from the practitioner respondents. It was comprised of three basic sections: 
- $\quad$ The first assessed evidence and importance of business skills/abilities.

- $\quad$ The second requested the respondents to rate, on a seven-point scale, student performance with respect to six business-related areas and issues, and then allowed the respondent to identify up to the three most important of these areas.

- The third section identified the background business or functional area of the respondent.

Finally, there was the aforementioned accommodation for open-end responses with respect to any issues of concern and the importance of interaction between the real business world and academia. The survey is attached in the Appendix.

\section{Results}

\section{Skills/Abilities Section}

Respondents were asked to review a list of nine skills/abilities that were deemed to be important both by the business school faculty and the AACSB International. The listed skills were: ability to work independently, quantitative, presentation, interpersonal, problem-solving, team-building, writing, computer, and critical thinking. Business panelists were asked to identify up to the three most prominent skills in each of the following three areas: (a) most important to professional development and advancement, (b) most clearly evident in a positive manner, and (c) least successfully displayed.

Table 1 summarizes the responses for skills panelists felt were "most important to professional development and advancement" and lists the skills in descending order on the basis of total mentions. In reading the first row of Table 1, we see that nine respondents (29 percent of the 31 respondents) rated problem-solving skills as most important. Six respondents also rated problem-solving skills as second most important, while six others rated these skills as third most important. There were 21 total mentions of interpersonal skills, or 67 percent of the 31 respondents named interpersonal skills as being important.

Table 1

Skills Most Important To Professional Development And Advancement

\begin{tabular}{|l|c|c|c|c|}
\hline \multicolumn{1}{|c|}{ Skill } & Most Important & $\mathbf{2}^{\text {nd }}$ Most & 3 $^{\text {rd }}$ Most & Total Mentions \\
\hline Problem-Solving & $9(29 \%)$ & $6(19 \%)$ & $6(19 \%)$ & $21(67 \%)$ \\
\hline Critical Thinking & $8(26 \%)$ & $6(19 \%)$ & $5(16 \%)$ & $19(61 \%)$ \\
\hline Interpersonal & $10(32 \%)$ & $9(29 \%)$ & 0 & $19(61 \%)$ \\
\hline Team-Building & $1(3 \%)$ & $7(23 \%)$ & $10(32 \%)$ & $18(58 \%)$ \\
\hline Presentation & 0 & $1(3 \%)$ & $5(16 \%)$ & $6(19 \%)$ \\
\hline Work Independently & $2(6 \%)$ & $2(6 \%)$ & $1(3 \%)$ & $5(16 \%)$ \\
\hline Writing & $1(3 \%)$ & 0 & $3(10 \%)$ & $4(13 \%)$ \\
\hline Quantitative & 0 & 0 & $1(3 \%)$ & $1(3 \%)$ \\
\hline Computer & 0 & 0 & 0 & 0 \\
\hline
\end{tabular}

The first four skills, problem-solving, critical thinking, interpersonal, and team-building, clearly dominated on the basis of total mentions of $21,19,19$, and 18 respectively. There is a precipitous fall-off to the next most mentioned skills, presentation, work independently, and writing with total mentions of six, five, and four respectively.

Upon having observed the class presentations, the respondents were next asked to select the three skills they felt were "most clearly evident in a positive manner" from the same list of nine skills. Table 2 summarizes the responses and lists the skills in descending order on the basis of total mentions. 
Table 2

Skills Most Clearly Evident In A Positive Manner

\begin{tabular}{|l|c|c|c|c|}
\hline \multicolumn{1}{|c|}{ Skill } & Most Positive & $\mathbf{2}^{\text {nd }}$ Most & $3^{\text {rd }}$ Most & Total Mentions \\
\hline Presentation & $4(13 \%)$ & $6(19 \%)$ & $2(6 \%)$ & $12(39 \%)$ \\
\hline Work Independently & $4(13 \%)$ & $5(16 \%)$ & $2(6 \%)$ & $11(36 \%)$ \\
\hline *Critical Thinking & $4(13 \%)$ & $3(10 \%)$ & $4(13 \%)$ & $11(36 \%)$ \\
\hline$*$ Team-Building & $8(26 \%)$ & $3(10 \%)$ & 0 & $11(36 \%)$ \\
\hline *Interpersonal & $5(16 \%)$ & $1(3 \%)$ & $3(10 \%)$ & $9(29 \%)$ \\
\hline *Problem-Solving & $2(6 \%)$ & $2(6 \%)$ & $2(6 \%)$ & $6(19 \%)$ \\
\hline Computer & $2(6 \%)$ & $1(3 \%)$ & $3(10 \%)$ & $6(19 \%)$ \\
\hline Quantitative & $1(3 \%)$ & $1(3 \%)$ & 0 & $2(6 \%)$ \\
\hline Writing & 0 & $1(3 \%)$ & $1(3 \%)$ & $2(6 \%)$ \\
\hline None & $1(3 \%)$ & $8(26 \%)$ & $14(45 \%)$ & Not Meaningful \\
\hline
\end{tabular}

* These skills were identified as being most important in Table 1.

There is a more even distribution in the identification of positive skills in Table 2 than in the identification of important skills represented in Table 1. Recall that in Table 1, the most important skills were clearly identified as (a) problem-solving, (b) critical thinking, (c) interpersonal skills, and (d) team-building. Support for positive evidence of these more important skills from Table 1 appears to be lukewarm. In Table 2, total positive mentions of these more important skills ranged from 19 percent for problem-solving to $36 \%$ for critical thinking and teambuilding skills. Another indicator of the less than enthusiastic identification of positive skills is the number of raters or respondents who skipped or failed to rate skills. In Table 1, all 31 respondents named three skills that they felt were most important to professional development and advancement. With respect to the data in Table 2 , 1 respondent of the 31 did not list any positive skills, 7 listed only one positive skill, 6 listed two positive skills, and 17 listed three positive skills.

Table 3 is somewhat difficult to interpret, but contains interesting information. It summarizes the assessments of positive evidence of skills across each skill that was deemed to be important to professional development and advancement. The rows are the skills that were considered to be important, and the columns are these same skills that were rated positively by the respondents. The row total for the first row, problem-solving, is 21. This corresponds to the 21 respondents who named problem-solving as one of three important skills as shown in Table 1. Indeed, all row totals in Table 3 correspond exactly to the total mentions shown for the same rows of Table 1. The remaining numbers in the first row of Table 3 are proportions, and each represents the proportion of the 21 who named the column heading skill as being one that was evident in a positive manner. For example, of the 21 who named problem-solving as an important skill, .19 or 19 percent noted positive evidence of problem-solving during class presentations. In like manner, of these same 21, 33 percent noted positive evidence of critical thinking, 38 percent noted evidence of interpersonal skills, and so on. The proportions (percents) in any row do not sum to $1.00(100 \%)$ because respondents were allowed to name up to three skills that were evident in a positive manner. 
Table 3

Relationships Among Assessments Of Important Skills And Positive Evidence Of All Skills

\begin{tabular}{|c|c|c|c|c|c|c|c|c|c|c|}
\hline $\begin{array}{l}\text { Positive } \rightarrow \\
\text { Important } \downarrow\end{array}$ & $\begin{array}{l}\text { Problem- } \\
\text { Solving }\end{array}$ & $\begin{array}{l}\text { Critical } \\
\text { Thinking }\end{array}$ & $\begin{array}{c}\text { Inter- } \\
\text { personal }\end{array}$ & $\begin{array}{l}\text { Team- } \\
\text { Building }\end{array}$ & $\begin{array}{l}\text { Present- } \\
\text { ation }\end{array}$ & $\begin{array}{c}\text { Work } \\
\text { Independ- } \\
\text { ently }\end{array}$ & Writing & $\begin{array}{l}\text { Quanti- } \\
\text { tative }\end{array}$ & $\begin{array}{l}\text { Comp- } \\
\text { uter }\end{array}$ & $\begin{array}{l}\text { Row } \\
\text { Total }\end{array}$ \\
\hline $\begin{array}{l}\text { *Problem- } \\
\text { Solving }\end{array}$ & .19 & .33 & .38 & .33 & .33 & .33 & .05 & .05 & .14 & 21 \\
\hline $\begin{array}{l}* \text { Critical } \\
\text { Thinking }\end{array}$ & .21 & .42 & .26 & .42 & .47 & .37 & .05 & .11 & .21 & 19 \\
\hline *Interpersonal & .11 & .26 & .32 & .37 & .26 & .37 & .05 & .05 & .21 & 19 \\
\hline *Team-Building & .22 & .33 & .22 & .44 & .39 & .28 & .11 & .06 & .28 & 18 \\
\hline Presentation & .33 & .50 & .33 & 0 & .67 & .50 & .33 & .17 & .33 & 6 \\
\hline $\begin{array}{l}\text { Work } \\
\text { Independently }\end{array}$ & .40 & .60 & .40 & .40 & .60 & .20 & 0 & 0 & 0 & 5 \\
\hline Writing & 0 & .25 & 0 & .25 & .25 & .50 & 0 & 0 & .25 & 4 \\
\hline Quantitative & 0 & 0 & 0 & 0 & 0 & 1.00 & 0 & 0 & 0 & 1 \\
\hline Computer & - & - & - & - & - & - & - & - & - & 0 \\
\hline
\end{tabular}

* These skills were identified as being most important in Table 1.

It would seem to be a desirable situation if the raters who identified a particular skill as being important also noted positive evidence of that skill. Were this the case, the main diagonal of Table 3 would contain the largest proportions. Another way of stating this is that it would be nice if the intersection of a skill's row and that same skill's column contained the highest proportion in that row. Table 4 is shown to depict exactly this kind of information.

Table 4

Assessments Of Important Skills And Positive Evidence Of That Particular Skill

\begin{tabular}{|l|c|c|}
\hline \multicolumn{1}{|c|}{ Skill/Ability } & Number Who Rated Skill As Important & Percent Who Noted Evidence of Skill \\
\hline Problem-Solving & 21 & $19 \%$ \\
\hline Critical Thinking & 19 & $42 \%$ \\
\hline Interpersonal & 19 & $32 \%$ \\
\hline Team-Building & 18 & $44 \%$ \\
\hline Presentation & 6 & $67 \%$ \\
\hline Work Independently & 5 & $20 \%$ \\
\hline Writing & 4 & $0 \%$ \\
\hline Quantitative & 1 & $0 \%$ \\
\hline Computer & 0 & - \\
\hline
\end{tabular}

For example, viewing the skills that were identified as being most important, we note that of the 21 respondents who identified problem-solving as an important skill, 19 percent (4 of the 21 respondents) noted positive evidence of it. Nineteen respondents named critical thinking as an important skill, and $42 \%$ of these noted positive evidence of this skill during the class presentation.

There are several possible reasons for skills not having been identified as "positively evident" during class presentations. Note that writing skills were mentioned only twice as having been evident in a positive manner. This may be in part due to the fact that some respondents (business practitioners) observed presentations, but did not read the case write-ups or final papers. It must also be kept in mind that the respondents observed student group presentations during a single class. The case studies presented in any class may or may not have emphasized problem-solving and/or the need for interpersonal skills. As expected, some of the cases emphasized finance; others emphasized marketing, human resource management, corporate culture, or a variety of other "hard" or "soft" business-related issues. Additionally, it would be very difficult for a business practitioner observer to assess the degree to which students worked independently or employed critical thinking and team-building skills. 
Respondents were next asked to identify up to three skills that were "least successfully displayed" during class presentations. Table 5 summarizes these results in descending order by total mentions.

Table 5

Skills Least Successfully Displayed

\begin{tabular}{|l|c|c|c|c|}
\hline \multicolumn{1}{|c|}{ Skill } & Least Successful & $\mathbf{2}^{\text {nd }}$ Least & $\mathbf{3}^{\text {rd }}$ Least & Total Mentions \\
\hline Quantitative & $3(10 \%)$ & $5(16 \%)$ & 0 & $8(26 \%)$ \\
\hline Computer & $3(10 \%)$ & 0 & $2(6 \%)$ & $5(16 \%)$ \\
\hline$*$ Team-Building & $3(10 \%)$ & $1(3 \%)$ & $1(3 \%)$ & $5(16 \%)$ \\
\hline Writing & $3(10 \%)$ & $1(3 \%)$ & 0 & $4(13 \%)$ \\
\hline$*$ Interpersonal & $2(6 \%)$ & $2(6 \%)$ & 0 & $4(13 \%)$ \\
\hline Work Independently & $2(6 \%)$ & $1(3 \%)$ & 0 & $3(10 \%)$ \\
\hline *Problem-Solving & $1(3 \%)$ & $1(3 \%)$ & $1(3 \%)$ & $3(10 \%)$ \\
\hline Presentation & $2(6 \%)$ & $1(3 \%)$ & 0 & $3(10 \%)$ \\
\hline *Critical Thinking & $1(3 \%)$ & 0 & 0 & $1(3 \%)$ \\
\hline None & $11(36 \%)$ & $19(61 \%)$ & $27(87 \%)$ & Not Meaningful \\
\hline
\end{tabular}

*These skills were identified as being most important in Table 1.

We were pleased to note that the respondents were not enthusiastic in listing skills unsuccessfully displayed. The most mentioned least successfully displayed skill was quantitative, with only eight total mentions. No other skill had more than five mentions. Further, 11 respondents did not name any skills as being unsuccessfully displayed, 8 respondents listed only one skill, 8 listed two skills, and only 4 listed three skills as being unsuccessfully displayed.

\section{Business-Related Issues and Areas}

In this second section of the survey, respondents were requested to rate, on a seven point scale, student performance with respect to the following six business-related areas and issues: international/global, cultural diversity, general understanding of business, business ethics, environmental concerns, and specific functional areas of business. Table 6 below presents the results of these ratings, and orders the business-related issues and areas in descending order by average rating.

Table 6

Performance Ratings Of Business-Related Issues

$[1=$ Not Successful ... 7=Very Successful $]$

\begin{tabular}{|l|c|c|c|c|c|}
\hline & N & Min & Max & Mean & Std. Dev. \\
\hline Business Ethics, Moral Values & 24 & 4 & 7 & 5.92 & 1.02 \\
\hline Specific Functional Areas of Business & 27 & 4 & 7 & 5.67 & .92 \\
\hline General Understanding of Business & 27 & 3 & 7 & 5.59 & 1.08 \\
\hline Cultural Diversity & 14 & 4 & 7 & 5.50 & .94 \\
\hline Environmental & 8 & 4 & 7 & 5.38 & 1.19 \\
\hline International/Global & 7 & 4 & 6 & 5.14 & .90 \\
\hline
\end{tabular}

Student performance was rated highest on business ethics with an average score of 5.92. Ratings of student performance on specific functional areas of business (5.67), general understanding of business (5.59), and cultural diversity (5.50) were tightly bunched. The average ratings for environmental issues (5.38) and international/global (5.14) were somewhat lower. It is noteworthy that all average ratings are quite positive - the lowest is 5.14 out of a possible 7.0. 
It is also interesting that the two lowest rated items, environmental and international/global issues also elicited the fewest responses (Ns) with 8 and 7 respectively out of the 31 respondents. It is possible that these issues were not important factors in the live case situations the students worked on. Or, it could be that the business panelists did not associate much importance to international/global or environmental issues. As unrealistic as that sounds, it will be seen to be the case as Table 7 below is examined.

The panelists were polled with respect to identifying the most important business-related areas from the same list that generated results shown in Table 6 above. The results are depicted in Table 7 and are listed in descending order by total mentions.

Table 7

Most Important Business-Related Issues/Areas

\begin{tabular}{|l|c|c|c|c|}
\hline \multicolumn{1}{|c|}{ Issue/Area } & $\mathbf{1}^{\text {st }}$ Most & $\mathbf{2}^{\text {nd }}$ Most & $\mathbf{3}^{\text {rd }}$ Most & Total Mentions \\
\hline Functional Areas of Business & $15(48 \%)$ & $11(36 \%)$ & $2(7 \%)$ & $28(91 \%)$ \\
\hline General Understanding of Business & $10(32 \%)$ & $9(29 \%)$ & $6(19 \%)$ & $25(80 \%)$ \\
\hline Business Ethics & $3(10 \%)$ & $6(19 \%)$ & $11(36 \%)$ & $20(65 \%)$ \\
\hline Cultural Diversity & $2(7 \%)$ & $1(3 \%)$ & $5(16 \%)$ & $8(26 \%)$ \\
\hline International/Global & 0 & 0 & $4(13 \%)$ & $4(13 \%)$ \\
\hline Environmental & 0 & $2(7 \%)$ & $1(3 \%)$ & $3(10 \%)$ \\
\hline No Mention & $1(3 \%)$ & $2(7 \%)$ & $2(7 \%)$ & Not Meaningful \\
\hline
\end{tabular}

Our real world business respondents clearly viewed three areas as being of primary importance:

- functional areas of business,

- $\quad$ general understanding of business, and

- $\quad$ business ethics.

The authors of this work are particularly surprised by the clear lack of consideration of international/global and environmental issues as being important. Cultural diversity also scored low, but that may be attributable to the fact that it has so many different meanings to various people. International/global and environmental issues are unambiguous terms. We in academia are continually asked by business leaders to increase our emphasis and coverage with respect to these areas, particularly the international/global issues. There is most certainly a disconnect somewhere, and these results will motivate us to gather more information in attempts to resolve these perplexing matters.

\section{Additional Written Feedback}

A number of the respondents took the opportunity to provide some written feedback. With few exceptions, the comments were very positive and provided additional evidence that the integrating experience is achieving its goals. The organizations were pleased with the opportunity to participate in the program and a number of them have done so more than once. The negative comments have been most useful as well. We judge some of the comments to be situation-specific and of limited use. However several suggestions were very useful, such as the need to check with the organization on a continuous basis during the course of the study and the desirability of submitting the written report prior to the presentation of the oral report. Some of the positive attributes and experiences noted by the respondents in the open-end comments were:

- $\quad$ Team did professional work.

- Team recommendations have been implemented at respondent organization.

- $\quad$ Student team was results-oriented.

- $\quad$ Team did excellent work in evaluating the respondent's company and making recommendations. 
- $\quad$ Student teams were enthusiastic, hard working, and dedicated.

- $\quad$ A positive educational experience for the students and the company.

\section{Background Business Areas of Respondents}

The only background information collected from the respondents concerned area of expertise or professional concentration in the business world. The results are presented in Table 8 . The reader will note that there are a large number of respondents from the not-for-profit sector. Recall that students are expected to obtain their own live case studies by contacting an organization and securing its cooperation. Since most of the students in the program are employed full-time many of these cases come from their own organizations. However, the business school regularly receives requests from local not-for-profits to help them with a business related problem on a volunteer basis. These requests are referred to the students in the strategy class as a possible project. Many of them are accepted by the students, and this is a win-win situation. In addition to fulfilling the need for live cases the school is able to provide a valuable community service that has received wide recognition and praise.

Table 8

Business Background Of Respondents

\begin{tabular}{|l|c|}
\hline \multicolumn{1}{|c|}{ Background in Business } & Frequency \\
\hline Not-For-Profit & 12 \\
\hline Marketing & 5 \\
\hline Human Resources Management & 4 \\
\hline Production/Operations & 3 \\
\hline Health Care & 2 \\
\hline Engineering & 2 \\
\hline Local, State, Federal Government & 1 \\
\hline Finance & 1 \\
\hline No Response & 1 \\
\hline
\end{tabular}

\section{Conclusions}

This exercise has been a very useful learning experience on two levels. First, we are pleased that a more effective way of soliciting feedback from an important stakeholder group in the business community has been uncovered. The initial efforts in this area were very disappointing and provided little useful information. Using our live business problem integrating experience as the springboard for this type of outcomes measurement has a great deal of potential. In this first stage, the respondents did not know that they were going to be surveyed. This "surprise" element may have led to some of the differences between what the business practitioners initially thought was important and what they ultimately observed and reported. In addition, forcing the respondents to limit their choices to three may have affected some of the results. We would like to follow-up on these issues by talking to some of the respondents and getting future participants involved in the evaluation process at the beginning of the projects.

In the future, we will control the number of not-for-profit organizations participating in the project. While many of our students are employed in not-for-profit environments, we are concerned that the over-representation of these organizations has had some effect on ratings of:

- $\quad$ the importance of skills for professional advancement,

- $\quad$ skills most (least) clearly evident in a positive manner, and

- $\quad$ the importance of and performances with respect to the business-related issues.

On the level of the feedback we actually received, there is some very good news. There is clear confirmation that the goals of the MBA curriculum remain important and relevant to the business community. In 
addition, we are pleased in general with the positive feedback that we have received on the degree to which achievement of those goals is being demonstrated to an outside group. This is encouraging.

\section{References}

1. AACSB Task Force on Outcome Measurement. (June, 1989). Report of the AACSB Task Force on Outcome Measurement.

2. $\quad$ AAHE Assessment Forum. (1996). 9 Principles of Good Practice for Assessing Student Learning.

3. Association to Advance Collegiate Schools of Business International. (2002). Business Accreditation Standards.

4. Banta, T.W. \& Associates. (1996). Making a Difference: Outcomes of a Decade of Assessment in Higher Education. San Francisco: Jossey-Bass.

5. Middle States Commission on Higher Education. (March, 2002). Assessment of Student Learning: Options and Resources. 


\section{Appendix}

Strategic Management Survey

Please refer to the list of SKILLS/ABILITIES below. Please respond to the following questions with respect to these skills and your impressions of student performance in the class you visited.
A. Ability To Work Independently
F. Team-building Skills
B. Quantitative Skills
G. Writing Skills
C. Presentation Skills
H. Computer Skills
D. Interpersonal Skills
I. Critical Thinking Skills
E. Problem-solving Skills

**Please use the letters $\mathbf{A}$ to I in your responses below**

1. Which three skills do you feel are MOST IMPORTANT TO PROFESSIONAL DEVELOPMENT AND ADVANCEMENT?

_ Most Important __ 2nd Most _ 3 rd Most

2. Regarding the class you visited or the team you interacted with, which skills (if any) were MOST CLEARLY EVIDENT IN A POSITIVE MANNER? [Please do not feel compelled to supply three responses: give 0, 1, 2, or 3 responses at your discretion.]

_ Most Positive __ 2nd Most _ _ 3rd Most

3. Regarding the class you visited or the team you interacted with, which skills (if any) were LEAST SUCCESSFULLY DISPLAYED? [Please do not feel compelled to supply three responses: give 0,1, 2, or 3 responses at your discretion.]

__ Least Successful ___ 2nd Least __ 3rd Least

4. Referring to the list of business-related issues/areas below. Please rate student performance with respect to these areas from $1=$ Not Successful to $7=$ Very Successful. Please leave blank if you have no impressions of student performance in an area.

\footnotetext{
A. International/Global Issues

B. Cultural Diversity Issues

C. General Understanding of Business

D. Business Ethics, Moral Issues

E. Environmental Issues

F. Specific Funct. Areas of Business

[Finance,Operations, Accounting,Marketing,

Management]
}

Not
Successful
1
1
1
1
1
1


5. Please review the above list. Which do you consider to be the 3 most important areas? (Use letters A.- F. below)

_ Most Important Area _ _ 2nd Most__ _ 3rd Most

6. Which ONE of the following best describes your background in the business world?

$\begin{array}{lll}\text { _Finance } & \text { _Accounting } & \text { _Marketing } \\ \text { __Health Care } & \text { __Production/Operations } & \text { _-MIS/Computers/Telecom } \\ \text { _Engineering } & \text { _Purchasing } & \text { _Not-For-Profit } \\ \text { __Local, State, Federal Govt } & \text { __Human Resources Management } & \\ \text { __Other__ } & \end{array}$

7. Please make any comments you like with respect to your interaction with the team of our MBA program, or "the bridge" between the real business world and academia, or anything you wish.

Notes 